\title{
PROFESSIONAL BOUNDARIES AND PSYCHOTHERAPY: A REVIEW
}

Dr Avinash De Sousa

Consultant Psychiatrist and Psychotherapist

Private Practice

Mumbai

E-mail: avinashdes999@yahoo.co.uk

ABSTRACT: Psychotherapy is a vital component of any treatment programme in the management of psychiatric disorders. It is very essential that the therapist receives adequate training prior to embarking on therapy with patients. There are various ethical issues and boundaries that the therapist must be aware of when dealing with psychiatric patients. Both experienced and novice therapist may experience confusion and dilemma when it comes across certain boundaries for the benefit of the patients. The present article introduces the readers the various boundaries that need to be maintained in psychotherapy and how the boundary is crossing or violations can lead to serious problems. The issue of gifts, fees, transference, physical contact between therapist and patient and sexual boundary violations are discussed. The need for focusing on boundaries in psychotherapy training is stressed.

Key words - professional boundaries, psychotherapy.

INTRODUCTION: Psychotherapy is defined as a form of psychological treatment where a trained therapist enters into a professional relationship with the patient, with the aim of reducing certain symptoms, removing certain symptoms and bringing about overall growth and development of the personality of the patient ${ }^{1}$. Psychotherapy is a professional relationship that helps patients in solving their own problems with their own efforts as well as that of the therapist. Psychotherapy treatments occur within a construct that has been termed as the therapeutic frame. A simple definition of professional boundaries is that they are the parameters defining the limits of a relationship in which one person (a patient or client) entrusts his or her welfare to another (a psychotherapist), and where fees or payments are made for the provision of a therapeutic service ${ }^{2}$. These boundaries suggest professional distance and respect which is a prerequisite of ethical professional behavior.

In the last decade, a renewed interest in psychotherapy has been seen in India. A larger number of psychiatric patients seek psychological interventions rather than medication as a cure for their problems. Hence psychotherapy today has found a permanent place in all treatment programs of psychiatric disorders. Psychotherapy pertains have not only had major psychiatric problems but also have various areas like school counseling in handling behavioral and parenting issues. Many couples seek psychotherapy to find a solution to their marital problems. Psychotherapists specialize in various forms of psychotherapy like cognitive therapy, rational emotive therapy and family therapy have increased in the last few years with more and more people realizing the long term value of psychotherapy in the treatment of psychological problems. 
Professional boundaries is a concept in psychotherapy which is essential, largely out of concern for the growing number of cases of sexual misconduct by therapists, which led to malpractice litigation and severe damage the reputation of mental health professionals ${ }^{3}$. There is a growing amount of cases of sexual misconduct being reported year after year where unqualified and untrained psychotherapists engage in both sexual and non-sexual boundary violations with their clients or patients ${ }^{4}$. This is more relevant in India, where patients present herself/himself whole heartedly to the therapist thinking him or her a knowledgeable and responsible for providing a cure for their problems. Therapists in some quarters are known to take advantage of such vulnerable patients.

THE CONCEPT OF BOUNDARY VIOLATION IN PSYCHOTHERAPY: There are namely two types of boundary violations noted in psychotherapy viz. the non-sexual boundary violations which is milder and the graver sexual boundary violations. Boundary crossings are benign phenomena that do not occur repetitively and are discussable between the therapist and the patient, while being non exploitative. Psychotherapy is a process where both the patent and therapist observe each other and share emotions. In Indian culture, the psychotherapist or doctor is often viewed as a demi-god who cures the patient. In such cases it is not unusual for patients to talk and enquire about the therapist's likes and dislikes or ask certain questions that may be personal during the course of therapy. Falling at the feet or touching the feet or sometimes kissing the hand of a doctor (who is perceived to be a healer) and cannot be viewed as a personal boundary crossing ${ }^{5}$. Many patients in therapy often enquire about the therapist, his native place, his family, what they do and whether he has children and how old they are. This is normal social enquiry that is rampant in our culture and must not be viewed as with a boundary crossing mindset.

It is normally seen that rigidity with respect to boundary crossings does no good for therapy. A good psychotherapist adjusts the treatment to the patient rather than expecting the patient to adjust to the treatment. Novice psychotherapists are trained and taught so much about boundaries in courses, that they show great concern about maintaining proper boundaries thereby becoming cold, rigid, formal and inapproachable in their way of dealing with the patients or clients. Some patients reject such therapists who behave more professional than human and do not generally follow up for therapy. Rigidity about boundaries serves as hindrance in developing a good rapport with the patient in therapy ${ }^{6}$. This is a common reason why novice therapists complain of a lack of follow up amongst their patients. Patients in India want a therapist who is friendly, homely and yet a guide and an advisor. In such cases the therapist has greater responsibility bestowed on him where he serves as an elder, friend, philosopher and guide for his patients. He may be looked upon in this role not only by the patients but also by the entire family of the patients. Rigidity and unfriendliness by the therapist in such cases will result in the patients seeking therapy elsewhere where he finds a therapist with the qualities he desires.

In psychotherapy, the beginning phase involves a period of adjustment where a sensitive psychotherapist needs to develop a comfort level of closeness or distance so that an appropriate 
therapeutic frame and environment conducive for therapy is created. This phase needs joint efforts by both the patients and the therapists. Some patients need a more talkative therapist, whereas others prefer a quiet and good listener. Some patients may appreciate the use of laughter, jokes and metaphors while some may feel ridiculed by the therapist when this is done. Good psychotherapists need an individualized approach with each patient throughout therapy. They vary their therapeutic style depending on the particular patient's need ${ }^{7}$.

Indian patients may be shy and reserved when it comes to opening up and discussing intense emotional issues with a new member in their circle i.e. the therapist. In such cases a slow, friendly and steady approach by the therapist shall boost the confidence of the patient in the therapist and shall improve their relationship in therapy. A therapist who shall hurry his patients to open up shall end up losing such a patient who may feel that the therapist does not understand the gravity and nature of the problem.

Many life events that occur with patient may need professional as well as a personal outlook. Sometimes there may be death of a figure to who he patient was extremely attached and the patient may expect a little extra sympathy or a patient listening from the therapist. Lack of sensitivity at such points of time may destroy any rapport that has been established and affect therapy as well. Sometimes therapy may seem to be going nowhere and therapists may get bored of their patients. At such times it may be seen that the therapist may seem disinterested in sessions and may look forward to hurry up sessions or prolong the time between consecutive appointments. All these phenomena may affect the patient who too observes therapist behavior just as the therapist observes patient behavior ${ }^{8}$. Many of our patients in India need someone who would listen to them so that they may express their emotions. Female patients coming from conservative and orthodox backgrounds often have problems expressing delicate issues and need a patience listening. At such times attitude like those mentioned above may be detrimental to the patients.

Boundary violations on the other hand, represent events or phenomena that are usually repetitive, harmful to the patient, and exploitative of the patient's dependent position in therapy. Sexual activity with the patient or engaging in a sexual relationship with a patient would be the gravest example. Other examples would be exploiting the patient financially or emotionally ${ }^{9}$. The psychotherapeutic relationship is by definition a relationship where there must be equal power with both the therapist and patient ${ }^{10}$. The psychotherapist is trained and paid to deliver a service based on skills acquired by specialized training. The patients may assume that whatever the therapist says or does is designed to help of the patient. As a result, many patients innocently succumb to boundary violations under the feeling that it is for their own good ${ }^{11}$.

A boundary transgression is used as an umbrella term that encompasses both boundary crossings and boundary violations ${ }^{12}$. Another term of note is boundary blurring which is used to describe instances in which the boundaries are confused but not enacted in the form of a boundary violation ${ }^{13}$. 
THE SETTING OF PSYCHOTHERAPY: In any consideration of psychotherapeutic boundaries one must take into account the setting in which therapy takes place. Therapy usually takes place in an office, clinic or hospital that is sufficiently private so that the patients feel comfortable to disclose embarrassing, sexual and shameful content ${ }^{14}$. Some patients prefer to sit on a comfortable chair or couch and talk while some prefer to walk while talking. Water, tea or coffee may be offered to the patients in the therapy room. A medically or terminally ill patients in a general hospital may require therapy at the bedside. The psychotherapy setting may change if some form of behavior therapy such as an exposure therapy is being applied in case of phobias and panic attacks. This may be the case in animal phobia, bus phobia or fear of the dark ${ }^{15}$. The setting may also change in case of a behavior therapy termed flooding used in obsessive compulsive disorder where dirt may be used.

In India, the doctor or therapist visiting the home of the patient is a common occurrence. The therapist as far as possible must conduct psychotherapy sessions in a clinic setting and must avoid visiting the house of the patient too often as chances of boundary violations occur. It happens many a time that a visit to the patient's house results in the therapist being offered lunch or dinner and a session that should last 30-45 mins may extend to a few hours building the chances for boundary violations and relationships other than that in a therapeutic frame. The therapist should refrain from becoming associated with various family members and relatives of the patients and must focus on the patients concerned. Even getting a rakhi tied by the patient though sacred as a relationship must be avoided as the therapist must maintain his frame of reference. Even traveling on a vacation with the patients and his or her family for counseling sessions there must be avoided.

THE ISSUE OF CONFIDENTIALITY IN PSYCHOTHERAPY: The fundamental principle in psychotherapy is one of confidentiality regarding what is spoken to the therapist. Patients may speak out content that they may associate with shame, guilt, remorse, self-loathing, fears of disapproval, and a host of other anxieties. The confidentiality reassurance allows them to open up in a manner that they probably would not even to their family members. Hence, confidentiality is regarded as the most important professional boundary ${ }^{16}$. The principle of confidentiality extends beyond not repeating what the patients say. Numerous cases exist in which a third party realized that the only source of specific information could have been from the patient, and there were justifiable feelings of violation or breach of privacy. A breach of confidentiality can make one vulnerable to litigation or to action from professional bodies that govern therapists ${ }^{17}$.

Sometimes in order to protect confidentiality, the therapist may have to lie to others outside the consulting room. He may have to pretend that he does not know information which has learned of solely through a patient. Over time, psychotherapists develop the capacity to compartmentalize certain information so as to keep it sequestered in a private sector of the psyche belonging to information heard during psychotherapy ${ }^{18}$. Confidentiality is not an absolute boundary. One is required to break confidentiality to report child abuse or any form of sexual abuse. A threat of imminent violence or suicide to an individual requires a 'duty to warn' exception to confidentiality ${ }^{19}$. 
Psychotherapists may meet and speak about a patient when there is a secret pleasure of treating a celebrity or a public figure. However, the notion of confidentiality should be construed as meaning that one cannot even reveal whether a specific patient is in treatment or not. However, when one presents a psychotherapy case for educational purpose or research and publication, one must be careful to disguise the identity of the patients. Moreover, even if consent is offered by the patient, identifying features must still be disguised so that an audience or reader does not recognize the patients ${ }^{20}$.

In India, confidentiality becomes a difficult issue because there are relatives and family members who often believe that nothing should be hidden from them and thus want to know whatever the patient has mentioned in therapy. Sometimes in cases of children and adolescents, the parents feel they have brought the child for therapy and actually pay the therapist his fees, hence they have a right to know what their child has disclosed. The same may be the case with the husband wife relationship in India. The therapist is sometimes in a quandary in such situations whether he must answer or not. The therapist must at such times not hurt anyone and keep in mind the sensitivity of both the patients and the relatives. The patients however, must be asked before disclosing anything to the relatives or family members.

THERAPIST SELF -DISCLOSURE IN PSYCHOTHERAPY: Therapists cannot be anonymous to the patient, no matter how hard they may try. The way they dress, the way they decorate their clinics, their facial expressions and the issues they choose to address when they speak all reveal a great deal about the therapist. The issue for the psychotherapist is not whether to self-disclose. The actual boundary concern is how much should one self-disclose. Feelings that the therapist may experience provides useful feedback for the patient. It would be far better to be an honest therapist that expresses what he feels than to be deliberately deceptive. Therapists often communicate feelings so that the patients may know what the therapist feels before the patients asks him or her ${ }^{21}$. One way of implementing a boundary on self-disclosure is to deliberately avoid sharing with the patients any details about one's personal life or family. Superficial elements like views on a political issue, a sport, a cricket match or studies may be needed at times. This may help in the rapport building process.

Self-disclosures about personal problems must be avoided. Some personal disclosures may be initially received well by the patients and therefore may mislead the therapists into thinking that such information is productive and useful. Small personal disclosures may often lead to greater intimacy and lead to the patients and therapists getting involved with each other either emotionally or sexually $^{22}$. In India, the therapist is viewed as a learned person and hence certain insights from the personal life of the therapist may actually give strength and confidence in certain areas to the patients. Thus therapists disclosure may be beneficial and must be used judiciously by the therapist.

THE PROFESSIONAL ATTITUDE AND PSYCHOTHERAPY: The concept of being a professional is fundamental to boundaries. The therapist is not a mother, father, priest, brother, son, lover or friend. 
In the first session and initial therapist-patient meetings, it is prudent to clarify what therapy is and what therapy is not. The therapist's professional role does not require that the therapist be excessively formal or inordinately depriving. The most important aspect is that psychotherapy is a scientific form of psychological treatment and this entails the professional aspect of the therapists, though in doing so therapy must not lose its humane touch ${ }^{23}$.

Another limit imposed on the professional therapist-patient relationship involves the duration of sessions. The time of the session is often 45-50 minutes but can be as brief as 15 minutes or as long as 90 minutes. In any case, the time parameters must be clear to the patient, and it is useful for the patient to understand from the beginning of the therapy that time constraints will always apply. Patients generally understand if the therapist explains that the session cannot be extended because there are other patients waiting to be seen. Sometimes one cannot be totally rigid, however, and occasionally may need to extend the time of sessions if the patient has just started to open out towards the end of a session or express an important facet of his or her problem or to accommodate an emotional reaction by a patient ${ }^{24}$. One must always have office assistants around when the patient is called as calling patients at odd hours may communicate to the patients that there is a potential for something other than a professional relationship. One must avoiding scheduling sessions on holidays or late at night and unless and emergent problems demands the same.

Therapy is hard work, and the therapist deserves to be paid. Fees are another aspect that conveys the professional aspect of therapy. The fact of being paid further differentiates the therapist from parent, lover, friend, and so on. In any case, therapists should carefully monitor their attitude about the patient's payment and the fee they are charging as a way of examining counter transference wishes to give the patient something for nothing. Novice or beginner therapists are typically conflicted about deserving a fee or how much to charge and this may be resolved after consulting a senior colleague $^{25}$.

GIFTS AND TOKENS OF APPRECIATION GIVEN BY THE PATIENT: Grateful patients may wish to express their appreciation by bringing gifts to their therapists. This may happen after they have had success at work which may be attributed to the therapy, found a new job or just returned from a vacation. Some wealthy patients may wish to make a donation to the institution where a therapist works. Patients may consciously or unconsciously feel that they are entitled to special dispensation because they have given money or other material gifts to a therapist. There are concerns about the potential of gifts to corrupt the therapeutic process and it is advisable to refuse all gifts. When a patient brings something handmade, a recommended book, a pen or a small memento, many therapists simply thank the patient for the gift and talk about the particular meaning or symbolism of gift. Patients who may not be able to afford a gift or feel that gifts are inappropriate will sometimes offer to provide service for the therapist like painting the clinic, bringing something from a shop the patient owns or some other service. In general, services from patients blend into the area of business transactions and dual relationships, which are almost always problematic in psychotherapy ${ }^{26}$. 
THE USE OF APPROPRIATE DRESSING AND LANGUAGE: Both dressing sense and language are aspects of the psychotherapist role that are often not studied as part of professional boundaries. Dressing in a professional manner conveys that the therapist is a professional. Patients sometimes quit after an initial session of a therapist as he does not appear like a seasoned professional therapist to them. Informal or crude language can also work against professionalism. The use of slangs may be problematic for some patients and one must exercise caution when using the same ${ }^{27}$.

PHYSICAL CONTACT ISSUES IN PSYCHOTHERAPY: In general, psychotherapy avoids physical contact. There is generally a handshake when a therapist and patient first meet. There are exceptions, of course, often based on cultural practices, so that some patients will initiate a handshake at the beginning and end of each session. Psychotherapists can return the handshake without concern about boundaries in most cases. Some therapists argue that a hug is sometimes needed by a patient, but people's capacity for self-deception is extraordinary. What a therapist may think is best for the patient may actually be a way of fulfilling the therapist's own needs ${ }^{28}$. The concept of a non- sexual hug is usually in the mind of the therapist but not necessarily in the mind of the patients.

PROFESSIONAL BOUNDARIES AFTER THE TERMINATION OF PSYCHOTHERAPY: Although there is a broad consensus that sexual contact between the psychotherapist and a patient is always unethical, the idea of post termination sexual relations has been somewhat more controversial ${ }^{29}$ The American Psychiatric Association determined in 1993 that any sexual relationship between a psychiatrist and former patient is unethical ${ }^{30}$. The American Psychological Association, on the other hand, allows for the possibility of a 2 year cooling-off period, after which it probably might be ethical for a therapist and a patient to begin a romantic or sexual relationship. Psychotherapy may often be terminated for the specific purpose of embarking on a romantic relationship ${ }^{31}$.

OTHER CRITICAL ISSUES IN PSYCHOTHERAPY: Transference involves the re-experiencing of the therapist and attributing emotions to the therapist was a powerful and authoritative figure from the past $^{32}$. Neurobiological studies demonstrate that representation of parents are laid down in neural networks that represent self and other from early in childhood, and then activated again and again by specific characteristics of current figures in one's life ${ }^{33}$. Transference may persist for a long time after therapy has been terminated ${ }^{34}$. In other words, the patient's dependency and vulnerability to exploitation does not disappear at termination of therapy.

As all experienced therapists know, patients who terminate psychotherapy frequently return for further therapeutic work in the midst of a life crisis or a struggle with a new developmental phase that must be mastered. Hence, an argument for an absolute prohibition against romantic involvement following 
termination is that the therapist may be needed again in the professional role of psychotherapist rather than as a friend, business partner, or lover. There may be areas of common interest that bring them together periodically as well. For example patients and mental health professionals may serve on committees together or be involved in organizing a conference or with social causes or non governmental organizations ${ }^{35}$.

PREVENTION AND EDUCATION REGARDING BOUNDARY VIOLATIONS: Education about professional boundaries is essential in the training of psychotherapists. By its very, nature, psychotherapy involves a radical form of privacy. Two people are meeting each other regularly behind closed doors, and one of them is confessing his or her darkest and most shameful secrets to the other. The atmosphere of emotional confession and acceptance fosters a rate kind of intimacy not often available outside of therapy. Boundaries cannot be taught simply as a list of rules. They need to be taught as part of clinical wisdom, integrating boundary notions into discussions of technique and the choices a therapist must make. This can be done by an effective mentor or trainer who is there to guide and support the therapist. In any case, prevention depends to a large extent on what the therapist does in pivotal moments. In the final analysis, therapists must be their own watchdogs to avoid professional boundary violations ${ }^{36}$.

CONCLUSIONS: In this review, professional boundaries in psychotherapy have been dissected as issues that every psychotherapist must be aware of. Different forms of psychotherapy are going to require different emphases on the way that the boundaries are implemented. Within different techniques, whether one uses gestalt therapy or cognitive therapy or psychodynamic methods coupled with behavior therapy, one adjusts the boundaries to make the patient more capable of collaborating with the therapist. One of the most difficult aspects of psychotherapeutic practice is our incapacity to know the ultimate impact of departing from boundaries. Nevertheless whenever boundary issues thwart psychotherapeutic practice they must be addressed.

\section{REFERENCES}

1. Pope KS, Vasquez MJT. Ethics in Psychotherapy and Counseling: A Practical Guide. John Wiley and Sons, 2011.

2. Georgaca E. Exploring signs and voices in the therapeutic space. Theory Psychol 2003; 13: $541-560$

3. Zur O. Boundaries in Psychotherapy: Ethical and Clinical Explorations. American Psychiatric Publishing; 2007. 
4. Celenza A. Sexual boundary violations: therapeutic, supervisory and academic contexts. Jason Aronson Inc; 2007.

5. Gutheil TG, Simon RI. Non sexual boundary crossings and boundary violations: the ethical dimension. Psychiatr Clin North Am 2002; 25(3): 585-592.

6. Sarkar SP. Boundary violation and sexual exploitation in psychiatry and psychotherapy: a review. Adv Psych Treat 2004; 10: 312-320.

7. Franzini LR. Humor in therapy: the case for training therapists in its uses and risks. J Gen Psychol 2001; 128(2): 170-193.

8. Goldberg A. Some limits of the boundary concept. Psychoanal Quart 2008; 77: 861-875.

9. Crowden A. Professional boundaries and the ethics of dual and multiple overlapping relationships in psychotherapy. Monash Bioeth Rev 2008; 27(4): 10-27.

10. McCabe R, Priebe S. The therapeutic relationship in the treatment of severe mental illness: a review of methods and findings. Int J Soc Psychiatry 2004; 50(2): 115-128.

11. Glass LL. The gray areas of boundary crossings and boundary violations. Am J Psychother 2005; 57(4): 429-444.

12. Pope KS, Keith-Speigel P. A practical approach to boundaries in psychotherapy: making decisions, bypassing blunders and mending fences. J Clin Psychol 2008; 64(5): 638-652.

13. Gutheil TG. Boundary issues and personality disorders. J Psychiatr Pract 2005; 11(2): 88-96.

14. Gabbard GO, Crisp-Han H. Teaching professional boundaries to psychiatric residents. Acad Psychiatry 2010; 34(5): 369-372.

15. Falsetti SA, Resnick HS, David JL. Multiple channel exposure therapy for women with PTSD and comorbid panic attacks. Cogn Behav Ther 2008; 37(2): 117-130.

16. Jain S, Roberts LW. Ethics in psychotherapy: a focus on professional boundaries and confidentiality practice. Psychiatr Clin North Am 2009; 32(2): 299-314.

17. Campbell AT. Consent, competence and confidentiality related to psychiatric conditions in adolescent medicine practice. Adolesc Med Clin 2006; 17(1): 25-47.

18. Pepper RS. Confidentiality and dual relationships in group psychotherapy. Int J Group Psychother 2004; 54(1): 103-114.

19. Mishara BL, Weisstub DN. Ethical and legal issues in suicide research. Int J Law Psychiatry 2005; 28(1): 23-41. 
20. Fonagy P. Psychotherapy research: do we know what works for whom. Br J Psychiatry 2010; 197: 83-85.

21. Fisher CD. Ethical issues in therapy: therapist self disclosure of sexual feelings. Ethics Behav 2004; 14(2): 105-121.

22. Henretty JR, Levitt HM. The role of therapist self disclosure in psychotherapy: a qualitative review. Clin Psychol Rev 2010; 30(1): 63-77.

23. Desousa A. Ethical issues in child and adolescent psychotherapy. Indian J Med Ethics 2010; 7(3): 157-161.

24. Hundert EM, Appelbaum PS. Boundaries in psychotherapy : model guidelines. Psychiatry 1995; 58(4): 345-356.

25. Newman SS. Considering fees in psychodynamic psychotherapy: opportunities for residents. Acad Psychiatry 2005; 29(1): 21-28.

26. Forrester K. What you see may not be what you get: beware of patients bearing gifts. J Law Med 2010; 18(2): 268-274.

27. Karasu TB. The ethics of psychotherapy. Am J Psychiatry 1980; 137(12): 1502-1512.

28. Willis M. Physical contact with child and adolescent psychiatric patients. Br J Psychiatry 2006; 189: 486-487.

29. Levine HB, Yanof JA. Boundaries and postanalytic contacts in institutes. J Am Psychoanal Assoc 2004; 52(3): 873-901.

30. American Psychiatric Association. Ethical guidelines for psychotherapy with psychiatric patients. American Psychiatric Publishing; 2001.

31. Gabbard GO. Psychotherapy in psychiatry. Int Rev Psychiatry 2007; 19(1): 5-12.

32. Kernberg OF, Yeomans FE, Clarkin JF, Levy KN. Transference focused psychotherapy : an overview and update. Int J Psychoanal 2008; 89(3): 601-620.

33. Bateman A, Fonagy P. The use of transference in dynamic psychotherapy. Am J Psychiatry 2007; 164(4): 680-682.

34. Gabbard GO. What is good enough termination? J Am Psychoanal Assoc 2009; 57(3): 575594.

35. Gabbard GO Bennett TJ. Dilemmas in the psychotherapy of sexually impulsive patients. Am J Psychiatry 2005; 162(5): 859-865. 
36. Douglas CJ. Teaching supportive psychotherapy to psychiatry residents. Am J Psychiatry 2008; 165(4): 445-452.

CONFLICT OF INTEREST: There is no Conflict of interest. 